\title{
Thyroid Nodule Size and Prediction of Cancer: A Study at Tertiary Care Hospital in Saudi Arabia
}

Hadi Afandi Al-Hakami ${ }^{1}$, Raneem Alqahtani ${ }^{2}$, Asim Alahmadi ${ }^{3}$, Dakheelallah Almutairi ${ }^{4}$, Mohammed Algarni ${ }^{5}$, Talal Alandejani 6,7

1. Otolaryngology, King Saud bin Abdulaziz University for Health Sciences, King Abdullah International Medical Research Center, Ministry of National Guard Health Affairs, Jeddah, SAU 2. Medicine, College of Medicine, King Saud Bin Abdulaziz University for Health Sciences, Jeddah, SAU 3. Otolaryngology, Ohud Hospital, Madinah, SAU 4. Otolaryngology, King Saud Bin Abdulaziz University for Health Sciences, King Abdullah International Medical Research Center, King Abdulaziz Medical City, Ministry of National Guard Health Affairs, Jeddah, SAU 5. Otolaryngology, King Saud Bin Abdulaziz University for Health Sciences, King Abdulaziz Medical City, Jeddah, SAU 6. Surgery, King Abdulaziz Medical City, Ministry of National Guard Health Affairs, Jeddah, SAU 7. Otolaryngology, King Saud Bin Abdulaziz University for Health Sciences, Jeddah, SAU

Corresponding author: Raneem Alqahtani, raneemalqahtani.96@gmail.com

\section{Abstract \\ Background}

Thyroid nodules have become relatively common in clinical practice, and their prevalence increases with age. The majority of thyroid nodules are benign, with $5-15 \%$ being malignant. There are a number of wellestablished predictors of malignancy in thyroid nodules, but thyroid nodule size has been a cause for concern for many researchers and results of the studies are still controversial about their probability of malignancy. Up to the current knowledge, there is no published study that evaluates if thyroid nodule size is associated with the risk of malignancy in Saudi Arabia, so in this study, we aim to find that.

\section{Methods}

This is a retrospective study of 987 patients who underwent thyroid nodule fine-needle aspiration (FNA) and subsequent thyroidectomy for thyroid nodules measuring $\geqslant 1 \mathrm{~cm}$.

\section{Results}

Thyroid cancer was more prevalent in males than females, and in patients who were older than or equal to 45 years. Nodular size of $1-1.9 \mathrm{~cm}$ was more prevalent among cancer patients than in benign cases $(\mathrm{p}<0.001)$.

\section{Conclusions}

Received 03/24/2020

Review began 03/25/2020 Review ended 03/25/2020 Published 03/30/2020

\section{() Copyright 2020}

Al-Hakami et al. This is an open access article distributed under the terms of the Creative Commons Attribution License CC-BY 4.0., which permits unrestricted use, distribution, and reproduction in any medium, provided the original author and source are credited.
The highest malignancy risk was observed in nodules $<2 \mathrm{~cm}$ and no increase in malignancy risk for nodules $>2 \mathrm{~cm}$. Nevertheless, when examined by type of thyroid malignancy, the rate of follicular carcinoma and other rare malignancy increased with increasing nodule size.

Categories: Endocrinology/Diabetes/Metabolism, Otolaryngology, Oncology

Keywords: thyroid nodule, malignancy risk, thyroid malignancy, thyroid, thyroid nodule size, fine-needle aspiration

\section{Introduction}

Thyroid nodules have become relatively common in clinical practice, and their prevalence increases with age. Before the introduction of routine imaging, thyroid nodules were found in approximately $5-10 \%$ of people by palpation alone [1]. The prevalence of thyroid nodules varies depending on age, gender, and geographic location, and now is estimated to be $20 \%$ to $60 \%$ [2, 3]. The majority of thyroid nodules are benign, with $5 \%$ to $15 \%$ being malignant [1]. Moreover, the worldwide incidence of thyroid cancer has been increasing over the past decade, due to the diagnosis of asymptomatic disease secondary to the advancement and improvement of diagnostic technology and increased surveillance [4]. The initial screening and triage of thyroid nodules are carried out using the fine needle aspiration (FNA), which has been broadly accepted as the most cost-effective and accurate tool [5]. Given that 70\% of aspirates return benign, FNA has proven to be of high value. However, $20-25 \%$ of samples return indeterminate, making FNA imperfect [6]. Prediction of thyroid malignancy is assisted by investigation of various clinical and radiological risk factors, including increased nodule height versus width, microcalcifications on ultrasonography, prior ionizing radiation exposure, nodule fixation, and firmness, hoarseness of voice, and age [1]. The nodule size has been a cause of concern for many researchers; some studies have reported an increased risk of malignancy with increasing nodule size, while many others denied an independent relationship. Nevertheless, data on the size of thyroid nodules as a determinant of carcinoma are still controversial. Different researches have been conducted for different aims. However, given the lack of published studies in Saudi Arabia, we aim to 


\section{Cureus}

determine the impact of nodule size on the risk of thyroid cancer.

\section{Materials And Methods}

After obtaining Institutional Review Board approval from the Regional Research and Ethics Committee at King Abdullah International Medical Research Center Western Region, we performed a retrospective review of 987 patients who presented with a thyroid nodule $(\geqslant 1 \mathrm{~cm})$, underwent thyroid nodule FNA and subsequent thyroidectomy by surgeons in the Division of Otolaryngology - Head and Neck Surgery from January 2010 to December 2018 at King Abdulaziz Medical City (KAMC) in Jeddah, Western Region, Saudi Arabia. A self-developed data collection sheet was created to collect and organize the recruited data. It included different items such as patient demographics, family history of thyroid cancer, number of nodules, nodule size by ultrasound, thyroid-stimulating hormone (TSH) level, results of FNA, type of surgical operation, as well as final histopathologic diagnosis. Fine needle aspiration biopsy (FNAB) results were categorized according to Bethesda classification as non-diagnostic (category I), benign (category II), atypia of undetermined significance (AUS)/ follicular lesion of undetermined significance (FLUS) (category III), follicular neoplasm/suspicious for a follicular neoplasm (category IV), suspicious for malignancy (category V), and malignancy (category VI) groups.

For data entry, Microsoft Office Excel (Microsoft Corporation, Redmond, US) was used, and Statistical Package Social Sciences (SPSS; IBM Inc., Armonk, US) software version 25.0 for data analysis. For statistical analysis, descriptive statistics and Pearson's chi-squared $(\chi 2)$ test were used, and missing data were excluded. Statistical significance was defined as a $p$-value of $<0.05$.

\section{Results}

A total of 987 patients presented with thyroid nodule $(\geqslant 1 \mathrm{~cm})$ underwent thyroid nodule FNA and subsequent thyroidectomy during the study period. As shown in Table 1, the studied patients comprised of 689 females (69.8\%) and 298 males (30.2\%). Their age ranged between 18-80 years, and (62\%) were aged 45 years and above. Five hundred sixty-seven patients (57.4\%) had multiple nodules, and 420 patients (42.6\%) had solitary nodules. Thyroid function was normal in almost all patients (93.9\%), and 270 patients (27.4\%) gave a positive family history of thyroid cancer. Nodules' size was equal or greater to $2 \mathrm{~cm}$ in $70.5 \%$ of the patients. Malignant nodules were found in $30.5 \%$ of the studied cases. Total thyroidectomy was found to be the most applied surgical operation on the sample cases occupying $65.5 \%$, followed by hemithyroidectomy $34.5 \%$.

\section{Characteristics}

Patients $(\mathrm{n}=987)[\mathrm{n}(\%)]$

Age (years)

$<45$

$\geq 45$

Mean \pm SD

Range

Gender

Females

Males

Number of nodules

Solitary

Multiple

567 (57.4)

Family history of thyroid cancer

Yes

$270(27.4)$

No

717 (72.6)

Thyroid function

Hypothyroid

Euthyroid

927 (93.9)

Hyperthyroid 


\section{Cureus}

\begin{tabular}{|lc} 
Distribution of FNA cytology & \\
Nondiagnostic or unsatisfactory & $71(7.2)$ \\
Benign & $355(36)$ \\
AUS/FLUS & $180(18.2)$ \\
Suspicious for a follicular neoplasm & $118(12)$ \\
Suspicious for Malignancy & $135(13.7)$ \\
Malignant & $128(13)$ \\
Diagnosis & \\
Benign & $686(69.5)$ \\
Malignant & $301(30.5)$ \\
Size of nodules (cm) & \\
$1.0-1.9$ & $291(29.5)$ \\
$2.0-2.9$ & $319(32.3)$ \\
$3.0-3.9$ & $214(21.7)$ \\
$\geq 4$ & $163(16.5)$ \\
Type of operation & $341(34.5)$ \\
Hemi thyroidectomy & $646(65.5)$ \\
Total thyroidectomy &
\end{tabular}

\section{TABLE 1: Demographic data of the patients}

SD - standard deviation; FNA - fine needle aspiration; AUS - atypia of undetermined significance; FLUS - follicular lesion of undetermined significance

The findings of the preoperative fine needle aspiration cytology (FNAC) showed that incidence of malignancy increases from $\mathrm{B}(\mathrm{I})$ to $\mathrm{B}(\mathrm{VI})$ with the highest malignancy incidence noted in $\mathrm{B}(\mathrm{VI})$ which is a good predictor of malignancy ( $\mathrm{p}<0.001$ ) (Figure 1$)$.

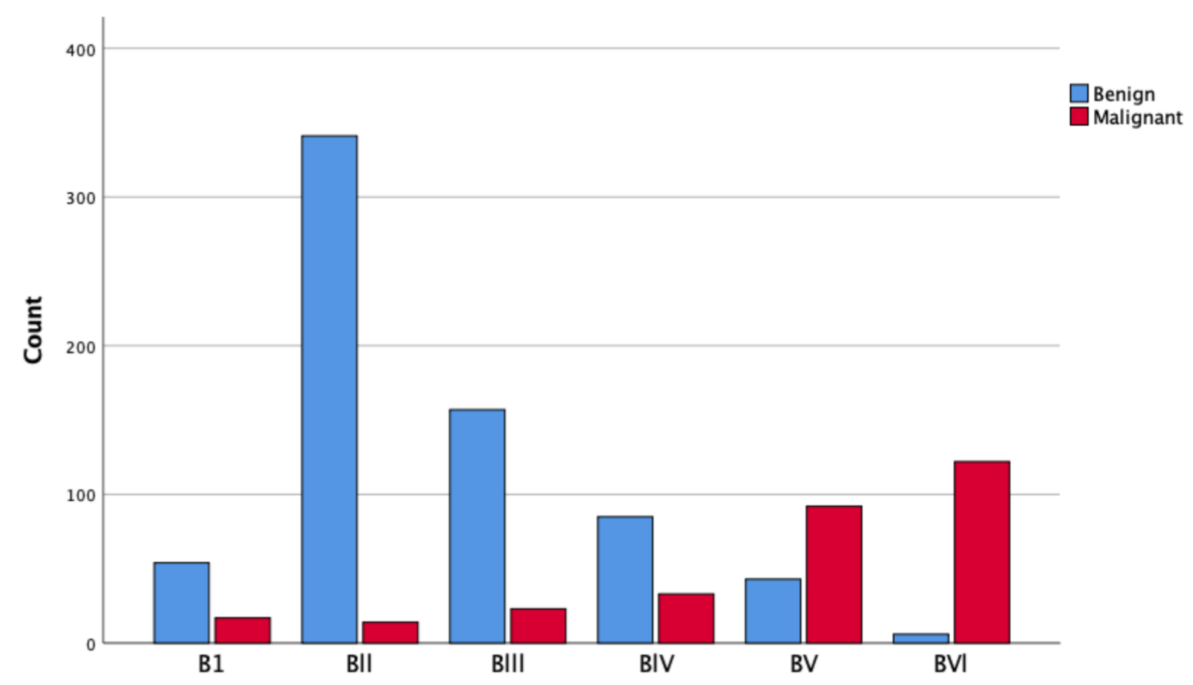

FIGURE 1: Correlation of fine needle aspiration (FNA) diagnosis based on Bethesda classification system with permanent histopathology results 


\section{Cureus}

A comparison between malignant and benign thyroid nodules is shown in Table 2; multiple factors were identified to be statistically significant variables. Malignant nodules were mostly prevalent in patients aged 45 and above $(\mathrm{p}<0.001)$. Benign thyroid nodules were found significantly higher in females, but the incidence of malignancy was higher in men $(\mathrm{p}<0.001)$. Regarding the number of nodules, the prevalence of malignancy in solitary thyroid nodules is higher than that of multinodular goiter $(\mathrm{p}<0.001)$. More patients with malignant nodules had a family history of thyroid cancer, and the majority of them had a normal thyroid function ( $\mathrm{p}<0.001$ ). Regarding nodular sizes, the cases with a nodular size of $1.0-1.9 \mathrm{~cm}$ were more prevalent among cancer patients than in benign cases $(\mathrm{p}<0.001)$.

\begin{tabular}{|c|c|c|c|}
\hline Characteristics & Cancer patients $(n=301)[n(\%)]$ & Benign patients $(n=686)[n(\%)]$ & $\mathbf{P}$ \\
\hline \multicolumn{4}{|l|}{ Age (years) } \\
\hline$<45$ & $78(25.9)$ & 297 (43.3) & \multirow{2}{*}{$<0.001$} \\
\hline$\geq 45$ & $223(74.1)$ & $389(56.7)$ & \\
\hline \multicolumn{4}{|l|}{ Gender } \\
\hline Females & $120(39.9)$ & 557 (81.2) & \multirow{2}{*}{$<0.001$} \\
\hline Males & $181(60.1)$ & $129(18.8)$ & \\
\hline \multicolumn{4}{|c|}{ Number of nodules } \\
\hline Solitary & $192(63.8)$ & $228(33.2)$ & \multirow{2}{*}{$<0.001$} \\
\hline Multiple & $109(36.2)$ & $458(66.8)$ & \\
\hline \multicolumn{4}{|c|}{ Family history of thyroid cancer } \\
\hline Yes & $174(57.8)$ & $96(14)$ & \multirow{2}{*}{$<0.001$} \\
\hline No & 127 (42.2) & $590(86)$ & \\
\hline \multicolumn{4}{|l|}{ Thyroid function } \\
\hline Hypothyroid & $4(1.3)$ & $12(1.7)$ & 0.631 \\
\hline Euthyroid & 295 (98) & $632(92.1)$ & $<0.001$ \\
\hline Hyperthyroid & $2(0.7)$ & $42(6.1)$ & 0.089 \\
\hline \multicolumn{4}{|c|}{ Size of nodules $(\mathrm{cm})$} \\
\hline $1.0-1.9$ & $195(64.8)$ & $96(14)$ & \multirow{4}{*}{$<0.001$} \\
\hline $2.0-2.9$ & $53(17.6)$ & 266 (38.8) & \\
\hline $3.0-3.9$ & 32 (10.6) & $182(26.5)$ & \\
\hline$\geq 4$ & $21(7)$ & $142(20.7)$ & \\
\hline \multicolumn{4}{|c|}{ Size of nodules $(\mathrm{cm})$} \\
\hline $1.0-1.9$ & $195(64.8)$ & $96(14)$ & \multirow{2}{*}{$<0.001$} \\
\hline$\geq 2$ & $106(35.2)$ & $590(86)$ & \\
\hline
\end{tabular}

TABLE 2: Comparison between cancer and benign patients with thyroid nodules regarding demographic and clinical characteristics

The postoperative histopathology results of 301 patients with malignant nodules are presented in Table 3 . Papillary carcinoma was the most common type of malignant nodules (85.4\%) followed by follicular carcinoma (8.3\%), medullary carcinoma (3\%), lymphoma (2\%), and lastly anaplastic carcinoma (1.3\%). 


\section{Cureus}

\section{Pathological diagnosis}

Papillary carcinoma

Follicular carcinoma

Medullary carcinoma

Lymphoma

Malignant anaplastic carcinoma
Patients ( $n=301)$ [n (\%)]

257 (85.4)

25 (8.3)

9 (3)

$6(2)$

$4(1.3)$

TABLE 3: Pathological diagnosis of the studied patients with malignant thyroid nodules

When the analysis of nodule size was compared with the type and distribution of thyroid malignancy, a significant relationship was detected. The majority of cancer cases, having a nodular size of $1.0-1.9 \mathrm{~cm}$, were diagnosed as papillary carcinoma, and $61.9 \%$ of cancerous nodules $\geqslant 4 \mathrm{~cm}$ were follicular carcinomas. Also, an increase in the proportion of the other rare types of malignancy, such as medullary, anaplastic carcinoma, and thyroid lymphoma was noted with increasing nodule size $(\mathrm{p}<0.001)$ (Table 4$)$.

\begin{tabular}{|c|c|c|c|c|}
\hline \multirow[t]{2}{*}{ Type of cancers } & \multicolumn{3}{|c|}{ Size of thyroid nodules of cancer patients $(n=301)$} & \multirow[b]{2}{*}{$\geq 4 \mathrm{~cm}(\mathrm{n}=21)$} \\
\hline & $1-1.9 \mathrm{~cm}(\mathrm{n}=195)$ & $2-2.9 \mathrm{~cm}(n=53)$ & $3-3.9 \mathrm{~cm}(\mathrm{n}=32)$ & \\
\hline Papillary carcinoma & 194 (99.5) & $42(79.2)$ & $16(50)$ & $5(23.8)$ \\
\hline Follicular carcinoma & 0 & $3(5.7)$ & $9(28.1)$ & $13(61.9)$ \\
\hline Medullary carcinoma & $1(0.5)$ & $5(9.4)$ & $3(9.4)$ & 0 \\
\hline Lymphoma & 0 & $1(1.9)$ & $2(6.3)$ & $3(14.3)$ \\
\hline Malignant anaplastic carcinoma & 0 & $2(3.8)$ & $2(6.3)$ & 0 \\
\hline
\end{tabular}

TABLE 4: Frequency distributions of cancer types in relation to nodular size of cancer patients

\section{Discussion}

It is critical to detect and evaluate thyroid nodules for possible thyroid cancer because $5-15 \%$ of all thyroid nodules are histopathologically malignant [1]. In our study, we attempted to determine the relationship between nodule size and malignancy risk. We found out that thyroid cancer is more prevalent among patients ages 45 years and above as compared to patients aged below 45 years $(p<0.001)$. In concurrence with our findings, Hughes et al. and El-Gammal et al. reported similar results in their studies stating that thyroid cancer among patients aged greater than or equal to 45 years was statistically significant than those aged less than 45 years $[7,8]$. Also, Reynolds et al. documented that thyroid cancer was more prevalent among the old age group than in the younger age group [9]. Chen et al. did not agree with the findings. Instead, they reported that thyroid cancer is common among people aged 45 years and below [10]. Witczak et al. reported that the age difference between patients with malignant diseases and those with benign diseases is not significant [11].

Based on our study, male patients had a higher incidence of malignancy than female patients. In agreement with our study, Paul et al. reported that the incidence of malignancy is higher in men [12]. Moreover, Li et al. reported that the incidence of thyroid cancer in male patients was significantly higher than in female patients ( $p=0.003$ ) [13]. In contrast to our results, studies conducted by El-Gammal et al. and Witczak et al. reported a high incidence of malignancy more in females than males $[8,11]$. However, a study by Jaheen et al. found that the difference in the incidence of malignancy between men and women is not statistically significant [14].

Our study found that the highest malignancy risk was observed in nodules $<2 \mathrm{~cm}$ and no increase in malignancy risk for nodules $>2 \mathrm{~cm}$. Thyroid nodules $1.0-1.9 \mathrm{~cm}$ in diameter provided baseline cancer risk for comparison (64.8\% risk of cancer). The overall prevalence of cancer in nodules $2.0-2.9 \mathrm{~cm}$ was $17.6 \%$; in nodules $3.0-3.9 \mathrm{~cm}$ it was $10.6 \%$; and in nodules $4.0 \mathrm{~cm}$ it was $7 \%$, presenting with statistically significant difference $(\mathrm{p}<0.001)$. However, the primary influence of this association was the high malignancy rate in nodules $1.0-1.9 \mathrm{~cm}$. When comparing nodules $2.0-2.9 \mathrm{~cm}, 3.0-3.9 \mathrm{~cm}$, or $4.0 \mathrm{~cm}$, no difference in malignancy 
rate was demonstrated. This suggests a possible threshold effect. Hence, it's worth suggesting that thyroid nodule size up to $2 \mathrm{~cm}$ is associated with an increased risk of thyroid cancer, but further growth beyond $2 \mathrm{~cm}$ no longer influences cancer risk.

El-Gammal et al. and Kamran et al. reported similar findings that a notable threshold effect is detected at $\sim 2.0 \mathrm{~cm}$. However, further growth beyond $2 \mathrm{~cm}$ no longer impacts malignant risk [8, 15]. Moreover, AlbujaCruz et al. reported that there was no significant difference between the $>4 \mathrm{~cm}$ group and the $<4 \mathrm{~cm}$ group in terms of malignancy ( $p=0.91$ ) [15]. Moreover, Megwalu et al. have studied nodules $\geqslant 4 \mathrm{~cm}$ and have not detected an association between nodule size and malignancy $(p=0.7)$ [16]. In addition, Cavallo et al. reported that thyroid nodule size is inversely related to malignancy risk, as larger nodules have lower malignancy rates [17]. Also, McHenry et al. reported that nodule size does not appear to be an independent predictor of thyroid malignancy, suggesting that it should not be used in lieu of FNAB for therapeutic decision making [18]. Furthermore, Bohacek et al. suggested that there is no trend toward increased malignancy in larger nodules [19]. On the other hand, Kuru et al. found that the incidence of thyroid cancer was significantly higher in nodule size greater than or equal to $4 \mathrm{~cm} \mathrm{[20].} \mathrm{Carrillo} \mathrm{et} \mathrm{al.} \mathrm{reported} \mathrm{that} \mathrm{FNAB} \mathrm{results} \mathrm{were} \mathrm{highly}$ inaccurate in nodule $\geqslant 4 \mathrm{~cm}, 26$ of $52(50 \%)$ were reported as benign turned out to be malignant on final pathology [21]. Additionally, Shin et al. reported that large nodules have a higher pretest probability of malignancy [22]. Moreover, Smith-Bindman et al. reported that the risk of malignancy is higher in nodules $>2 \mathrm{~cm}$ compared with nodules under $1 \mathrm{~cm}$ [23]. Also, Hong et al. reported that the risk of malignancy differed according to the US pattern. In intermediate- and low-suspicion nodules, a large nodule size $(\geqslant 3 \mathrm{~cm})$ showed a higher malignancy risk than smaller nodules [24]. As seen, there are conflicting results from different studies. Hence, nodule size on its own is not a reliable variable for predicting malignancy, and deciding any medical interventions based on it would not be a correct approach.

Regarding the number of nodules, in our study, 987 study patients included 420 (42.6\%) with a solitary thyroid nodule and 567 (57.4\%) with multinodular goiter (MNG). The prevalence of thyroid cancer was statistically significant between solitary nodules and MNG $(\mathrm{p}<0.001)$. Out of the 567 patients with MNG, there were 458 patients with benign nodules and 109 patients with malignant nodules. On the contrary, out of 420 patients with solitary thyroid nodules, there were 192 patients with malignant nodules and 228 with benign nodules. Hence, we suggest that solitary thyroid nodules are a predictor of malignancy. In agreement with our study, Frates et al. reported that solitary nodules had a higher likelihood of malignancy than a nonsolitary nodule $(p<0.01)[25]$. Furthermore, Li et al. reported that the incidence of thyroid cancer in patients with a single nodule was significantly higher than in patients with multiple nodules $(p<0.001)$ [13]. Multinodular goiters have been known as a benign condition with a low risk of associated malignancy [26]. Nevertheless, Gandolfi et al. reported that MNG should no longer be considered an indicator of probable benign disease and should be assessed as if it were a solitary nodule [27]. Additionally, El-Gammal et al. found that MNG were statistically significant for malignancy compared to solitary thyroid nodules [8].

Moreover, in our study, we found that the majority of patients with thyroid cancer had serum TSH concentration in a normal range, and it was statistically significant $(\mathrm{p}<0.001)$. In agreement with our findings, El-Gammal et al. reported that all patients with thyroid cancer in their study had normal thyroid function [8]. In contrary, Li et al. reported that high serum TSH level is an independent risk factor of thyroid cancer [13].

When analysis of nodule size was compared with the type and distribution of thyroid malignancy, papillary carcinoma was predominant in nodular size of 1.0-1.9 cm, and follicular carcinoma was found significantly in nodule size $\geqslant 4 \mathrm{~cm}$. In agreement with our study, Kamran et al. found that increasing nodule size was associated with a lower proportion of papillary carcinomas $(p<0.01)$ [6]. However, El-Gammal et al. reported that papillary carcinoma was predominant in larger sizes $(\geqslant 2 \mathrm{~cm})[8]$.

\section{Conclusions}

To conclude, the findings of this study suggest that an increase in thyroid nodule size impacts cancer risk in a nonlinear fashion. A threshold is detected at $2 \mathrm{~cm}$, and extension beyond $2 \mathrm{~cm}$ does not influence cancer risk. Nevertheless, the risk of follicular carcinomas and other rare thyroid malignancies increases as nodules enlarge.

\section{Additional Information \\ Disclosures}

Human subjects: Consent was obtained by all participants in this study. King Abdullah International Medical Research Center issued approval RJ/051/J. Animal subjects: All authors have confirmed that this study did not involve animal subjects or tissue. Conflicts of interest: In compliance with the ICMJE uniform disclosure form, all authors declare the following: Payment/services info: All authors have declared that no financial support was received from any organization for the submitted work. Financial relationships: All authors have declared that they have no financial relationships at present or within the previous three years with any organizations that might have an interest in the submitted work. Other relationships: All authors have declared that there are no other relationships or activities that could appear to have influenced the 
submitted work.

\section{Acknowledgements}

We would like to thank the staff of the medical records at King Abdulaziz Medical City for their valuable efforts in retrieving medical records and maintaining their availability.

\section{References}

1. Alexander EK, Marqusee E, Orcutt J, et al.: Thyroid nodule shape and prediction of malignancy . Thyroid. 2004, 14:953-958. 10.1089/thy.2004.14.953

2. Brander A, Viikinkoski P, Tuuhea J, Voutilainen L, Kivisaari L: Clinical versus ultrasound examination of the thyroid gland in common clinical practice. J Clin Ultrasound. 1992, 20:37-42. 10.1002/jcu.1870200107

3. Brander AE, Viikinkoski VP, Nickels JI, Kivisaari LM: Importance of thyroid abnormalities detected at US screening: a 5-year follow-up. Radiology. 2000, 215:801-806. 10.1148/radiology.215.3.r00jn07801

4. Vaccarella S, Franceschi S, Bray F, et al.: Worldwide thyroid-cancer epidemic? The increasing impact of overdiagnosis. N Engl J Med. 2016, 375:614-617. 10.1056/NEJMp1604412

5. Raparia K, Min SK, Mody DR, et al.: Clinical outcomes for "suspicious" category in thyroid fine-needle aspiration biopsy: patient's sex and nodule size are possible predictors of malignancy. Arch Pathol Lab Med. 2009, 133:787-790.

6. Kamran SC, Marqusee E, Kim MI, et al.: Thyroid nodule size and prediction of cancer. J Clin Endocrinol Metab. 2013, 98:564-570. 10.1210/jc.2012-2968

7. Hughes DT, Haymart MR, Miller BS, Gauger PG, Doherty GM: The most commonly occurring papillary thyroid cancer in the United States is now a microcarcinoma in a patient older than 45 years. Thyroid. 2011, 21:231-239. 10.1089/thy.2010.0137

8. El-Gammal A, E-Balshy MA, Zahran KM: Relationship between thyroid nodule size and incidence of thyroid cancer. Menoufia Med J. 2019, 32:1142-1148. 10.4103/mmj.mmj_178_18

9. Reynolds RM, Jennifer W, Stockton DL, et al.: Changing trends in incidence and mortality of thyroid cancer in Scotland. Clin Endocrinol. 2005, 62:156-162. 10.1111/j.1365-2265.2004.02187.x

10. Chen AY, Jemal A, Ward EM: Increasing incidence of differentiated thyroid cancer in the United States, 1988-2005. Cancer. 2009, 115:3801-3807. 10.1002/cncr.24416

11. Witczak J, Taylor P, Chai J, et al.: Predicting malignancy in thyroid nodules: feasibility of a predictive model integrating clinical, biochemical, and ultrasound characteristics. Thyroid Res. 2016, 9:4. 10.1186/s13044016-0033-y

12. Paul P, Ali KA, Jasir M: Predictors of malignancy in solitary nodule thyroid . Int Surg J. 2017, 4:703-708. 10.18203/2349-2902.isj20170217

13. Li JZ, Jin YJ, Liu X, Zhang LY: Association between the serum TSH concentration and thyroid cancer incidence. Chin J Oncol. 2011, 33:921-924.

14. Jaheen H, Sakr M: Predictors of malignancy in patients with solitary and multiple thyroid nodules . J Surg. 2016, 12:105-110

15. Albuja-Cruz MB, Goldfarb M, Gondek S, Allan BJ, Lew JI: Reliability of fine-needle aspiration for thyroid nodules greater than or equal to $4 \mathrm{~cm}$. J Surg Res. 2013, 181:6-10. 10.1016/j.jss.2012.06.030

16. Megwalu UC: Risk of malignancy in thyroid nodules $4 \mathrm{~cm}$ or larger . Endocrinol Metab. 2017, 32:77-82 10.3803/EnM.2017.32.1.77

17. Cavallo A, Johnson DN, White MG, et al.: Throid nodule size at ultrasound as a predictor of malignancy and final pathologic size. Thyroid. 2017, 27:641-650. 10.1089/thy.2016.0336

18. McHenry CR, Huh ES, Machekano RN: Is nodule size an independent predictor of thyroid malignancy? Surgery. 2008, 144:1062-1069. 10.1016/i.surg.2008.07.021

19. Bohacek L, Milas M, Mitchell J, Siperstein A, Berber E : Diagnostic accuracy of surgeon-performed ultrasound-guided fine-needle aspiration of thyroid nodules. Ann Surg Oncol. 2012, 19:45-51. 10.1245/s10434-011-1807-z

20. Kuru B, Gulcelik NE, Gulcelik MA, Dincer H: The false-negative rate of fine-needle aspiration cytology for diagnosing thyroid carcinoma in thyroid nodules. Langenbecks Arch Surg. 2010, 395:127-132. 10.1007/s00423-009-0470-3

21. Carrillo JF, Frias-Mendivil M, Ochoa-Carrillo FJ, Ibarra M: Accuracy of fine-needle aspiration biopsy of the thyroid combined with an evaluation of clinical and radiologic factors. Otolaryngol Head Neck Surg. 2000, 122:917-921.

22. Shin J, Caragacianu D, Randolph G: Impact of nodule size onprevalence and post test probability of malignancy: a systemic review. Laryngoscope. 2015, 125:263-272. 10.1002/lary.24784

23. Smith-Bindman R, Lebda P, Feldstein VA, et al.: Risk of thyroid cancer based onthyroid ultrasound imaging characteristics: results of a populationbased study. JAMA Intern Med. 2013, 173:1788-1795. 10.1001/jamainternmed.2013.9245

24. Hong MJ, Na DG, Baek JH, Sung JY, Kim JH: Impact of nodule size on malignancy risk differs according to the ultrasonography pattern of thyroid nodules. Korean J Radiol. 2018, 19:534-541. 10.3348/kjr.2018.19.3.534

25. Frates MC, Benson CB, Doubilet PM, et al.: Prevalence and distribution of carcinomainpatients with solitary and multiple thyroid nodules on sonography. J Clin Endocrinol Metab. 2006, 91:3411-3417. 10.1210/jc.20060690

26. Pinchera A, Aghini-Lombardi F, Antonangeli L, Vitti P: Multinodular goiter. Epidemiology and prevention . Ann Ital Chir. 1996, 67:317-325.

27. Gandolfi PP, Frisina A, Raffa M, et al.: The incidence of thyroid carcinoma in multinodular goiter: retrospective analysis. Acta Biomed. 2004, 75:114-117. 